\title{
Transpiration Cooling Tests of Porous CMC in Hypersonic Flow
}

\author{
Thomas Reimer ${ }^{1}$ and Markus Kuhn ${ }^{2}$ \\ DLR, German Aerospace Center, Institute of Structures and Design, Stuttgart, Germany \\ Ali Gülhan ${ }^{3}$ and Burkhard Esser ${ }^{4}$ \\ DLR, German Aerospace Center, Institute of Aerodynamics and Fluid Flow, Cologne, Germany \\ Martin Sippel ${ }^{5}$ and Arnold van Foreest ${ }^{6}$ \\ DLR, German Aerospace Center, Institute of Space Systems, Bremen, Germany
}

\begin{abstract}
During hypersonic flight the temperatures on the vehicle can reach very high values in certain locations. A hypersonic flight vehicle needs to be designed aerodynamically efficient. That results in rather small nose and leading edge radii which drives up thermal loads due to the fact that the loads depend on the curvature radius of these elements. Therefore thermal protections is required for these elements. However, even ceramics reach their use temperature limits when e.g. the leading edge radius of a space plane is in the order of only a few centimeters. Transpiration cooling could be a means to handle the thermal loads in certain critical locations for a hypersonic flight vehicle. This paper describes the loads derived for a conceptual space plane vehicle, the SpaceLiner, and also reports on the initial tests for transpiration cooling of ceramic matrix composites in the hypersonic flow of an arc jet facility.
\end{abstract}

\section{Introduction}

Sustained hypersonic flight generates considerable thermal loads on the surface of the vehicle. Depending on the type of vehicle and the propulsion system used, critical elements of the flight vehicle include the nose, leading edges of wings and control surfaces and in the case of airbreathing propulsion also structural elements of the engine intakes. Due to aerodynamic performance requirements, the affected structures of hypersonic vehicles are as a consequence designed with small nose or leading edge radii, in other words they are sharp. Since the heat loads on these critical elements depend on the radius of curvature, the goal to optimize performance drives up the thermal loads above levels that can be handled by conventional thermal protection systems. Thermal protection systems that are currently in use on e.g. the Space Shuttle are limited to temperatures of roughly $1600^{\circ} \mathrm{C}$. These temperatures are the result of a heat flux of around $600 \mathrm{~kW} / \mathrm{m}^{2}$ when radiation adiabatic conditions are assumed. However, the nose radius of the Shuttle is large compared to the envisioned systems used on hypersonic vehicles. When the heat flux $q$ is calculated using the DKR formulation.

$$
\dot{q}=\frac{a}{\left(R_{N}\right)^{0,5}}\left(\frac{\rho_{\infty}}{\rho_{S L}}\right)^{0,5}\left(\frac{U_{\infty}}{U_{C O}}\right)^{3,15}
$$

reported in Ref. 1 and taking into account smaller curvature radii it can quickly reach values of $10 \mathrm{MW} / \mathrm{m}^{2}$ and more. In that formulation RN is the nose radius, $\rho \infty$ is the density at a certain altitude, $\rho S L$ is the density at sea level, $\mathrm{U} \infty$ is the actual velocity of the vehicle at that altitude and UCO is the circular orbital velocity of the re-entry vehicle; $\mathrm{a}$ is a constant factor.

\footnotetext{
${ }^{1}$ Scientific Engineer, Space Systems Integration, Pfaffenwaldring 38-40, D-70569 Stuttgart, Germany

${ }^{2}$ Scientific Engineer, Space Systems Integration, Pfaffenwaldring 38-40, D-70569 Stuttgart, Germany

${ }^{3}$ Department Head, Supersonic and Hypersonic Technology, Linder Höhe, D-51147 Köln, Germany

${ }^{4}$ Scientific Engineer, Supersonic and Hypersonic Technology, Linder Höhe, D-51147 Köln, Germany

${ }^{5}$ Department Head, Space Transportation Analysis, Robert-Hooke-Str.7, D-28359 Bremen, Germany

${ }^{6}$ Scientific Engineer, Space Transportation Analysis, Robert-Hooke-Str.7, D-28359 Bremen, Germany
} 


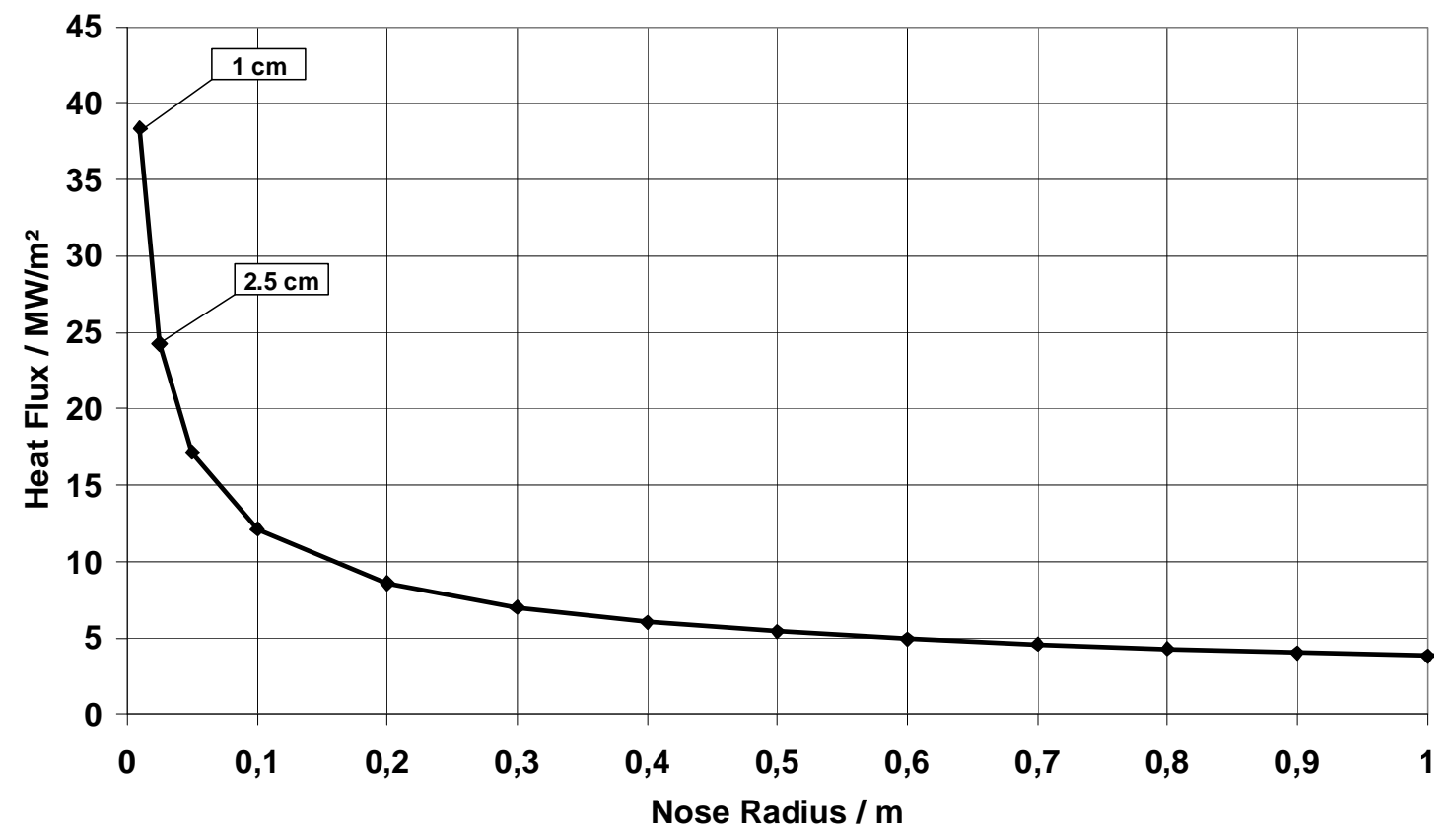

Figure 1. Heat flux depending on nose radius according to DKR formulation

At these levels of heat load, typically ablative TPS materials are used. However, in the case of sustained hypersonic flight that is not desirable because the surface ablation of the TPS changes the aerodynamic qualities of the vehicle and reduces performance.

There are new developments for advanced TPS designs based on CMC materials with higher application temperatures. For instance, the developments employing DLR's C/C-SiC material aim at higher use temperatures in the range of $1700-1800^{\circ} \mathrm{C}$. These systems were developed for re-usable entry vehicles like X-38 ${ }^{2}$ but also for single-flight items like ballistic capsules represented by EXPRESS ${ }^{3}$ and EXPERT ${ }^{4}$ and also for a radically new approach based on the use of facetted surface elements in the SHEFEX project ${ }^{5}$.

Another material option to cope with the challenges of sustained hypersonic flight could be Ultra-HighTemperature Ceramics (UHTC). These are ceramic compounds fabricated from rare earths with a high melting point like typically Zirconia, Hafnium or Boron with additions of other elements like carbides from Silicon. But also these types of ceramics suffer from degradation effects like oxidation at high temperature and still need to be improved until they may be used to produce the kind of structures required on hypersonic vehicles ${ }^{6}$.

In view of the problems with high heat loads and passive TPS designs, active cooling of critical elements of hypersonic vehicles therefore seems to be another possibility to solve the problem. Active cooling designs of thermal protection elements have been investigated for a considerable time. It was proposed for metallic TPS designs in critical areas but it did not make it from the drawing boards into flight hardware, different from the situation with liquid fuelled rocket engines where regenerative cooling of metallic thrust chambers and nozzles is state of the art.

In recent years there have been efforts to revive active cooling concepts in the field of thermal protection by choosing ceramics as the structural material and there were also quite successful developments of cooling technologies for rocket thrust chambers employing porous ceramic materials. These developments focus on the use of porous ceramic matrix composites (CMC) to design a transpiration cooling system which feeds a certain amount of coolant through the wall of the structure in order to keep it at an acceptable temperature. Also transpiration cooling as a special case of active cooling is not new, it has been followed for a long time, however, the investigations mainly concentrated on porous metals.

The development of a transpiration cooled ceramic thrust chamber for rocket propulsion showed that the technology in principle has a big potential for applications in ultra-high thermal load environments ${ }^{7}$. Tests were carried out with a demonstrator engine that showed the feasibility of the system. Typical heat flux values in rocket 
engine thrust chambers are in the order of $20-50 \mathrm{MW} / \mathrm{m}^{2}$. That order of magnitude is comparable to that expected for critical areas of hypersonic flight vehicles.

The technology of active transpiration cooling shall now be adapted to be applied to critical elements of hypersonic vehicles. Since the conditions of hypersonic flight are in part very different to those of rocket engines there has to be a development effort. In the case of rocket propulsion the coolant of choice was the cryogenic fuel because it still adds to the thrust of the engine. In the case of hypersonic flight the coolant can purely be selected based on its cooling efficiency. For the investigations presented here, the coolant will be water as the basic media, with possibly a limited number of trials being carried out using gases. Water as a coolant for transpiration cooling in a hypersonic flow regime showed promising results in earlier trials ${ }^{8}$.

\section{The SpaceLiner Conceptual Vehicle}

A base concept as a reference guideline for the development of the technology is the SpaceLiner vehicle proposed by DLR ${ }^{9}$. The Space Liner is a passenger vehicle capable of transporting 50 passengers long distance from Europe to Australia within 90 minutes.

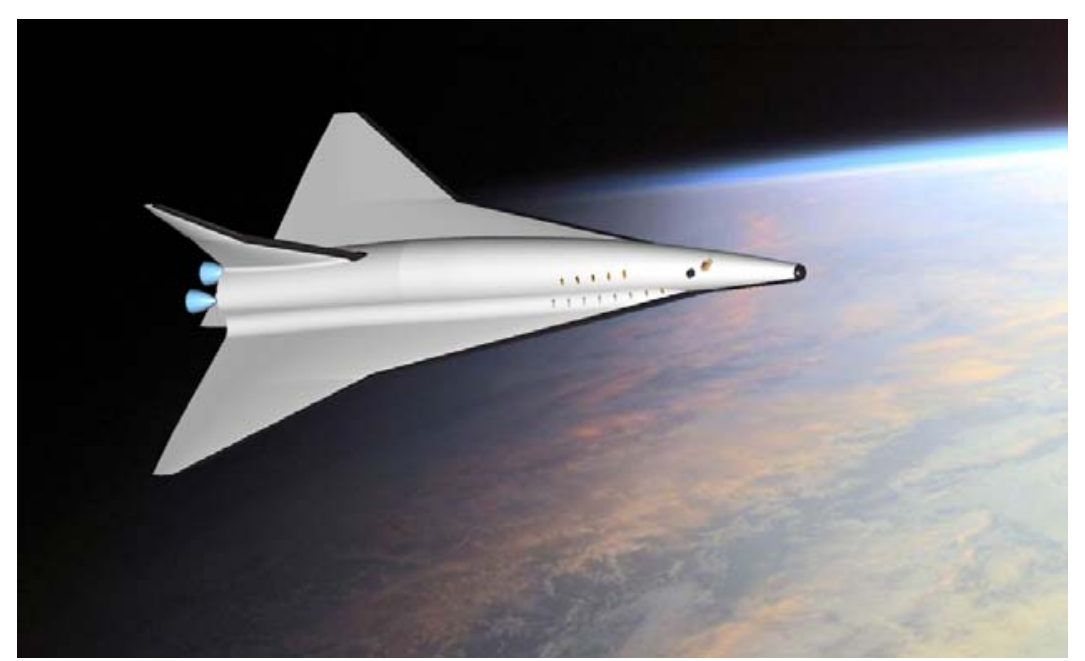

Figure 2. Artist's view of the SpaceLiner passenger stage.

The configuration is a parallel two-stage vehicle that performs a sub-orbital flight. The launch is carried out in the vertical mode, as a conventional rocket launch. The first stage is the larger one and acts as the booster stage for the passenger stage that continues the flight up to the destination. Total take-off mass of the system is around 1150 metric tones. The length of the booster is over $70 \mathrm{~m}$, the length of the passenger stage is $60 \mathrm{~m}$.

After the powered ascent to just over $90 \mathrm{~km}$ altitude the passenger stage basically performs a lifting re-entry. However, the difference to conventional winged vehicles like the Space Shuttle is that the trajectory of the SpaceLiner passenger stage is designed as a skipping flight path in the upper regions of the atmosphere. That means that the passenger stage dives into the atmosphere down to an altitude of roughly $45 \mathrm{~km}$ in the first skipping maneuver and then again pulls up to higher altitudes to repeat the cycle for a number of times with steadily decreasing top and low altitudes. The trajectory in terms of altitude over time is presented in Fig.3. 


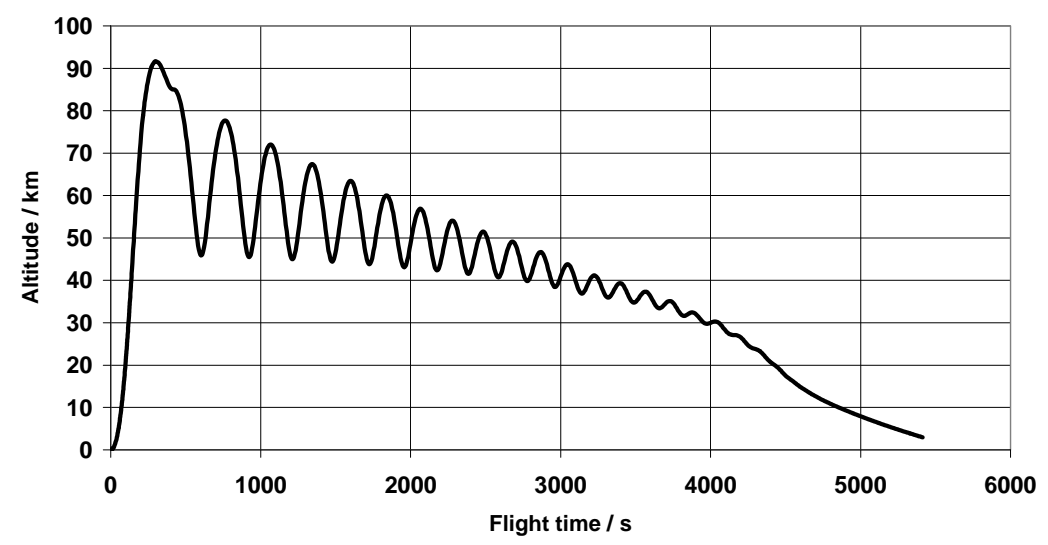

Figure 3. SpaceLiner trajectory as altitude over flight time

The heat flux history for the nose of the vehicle was calculated for a nose radius of $1 \mathrm{~m}$ based on the assumption of adiabatic conditions and pure radiation cooling with an emissivity value of 0.85 and is presented in Fig.4.

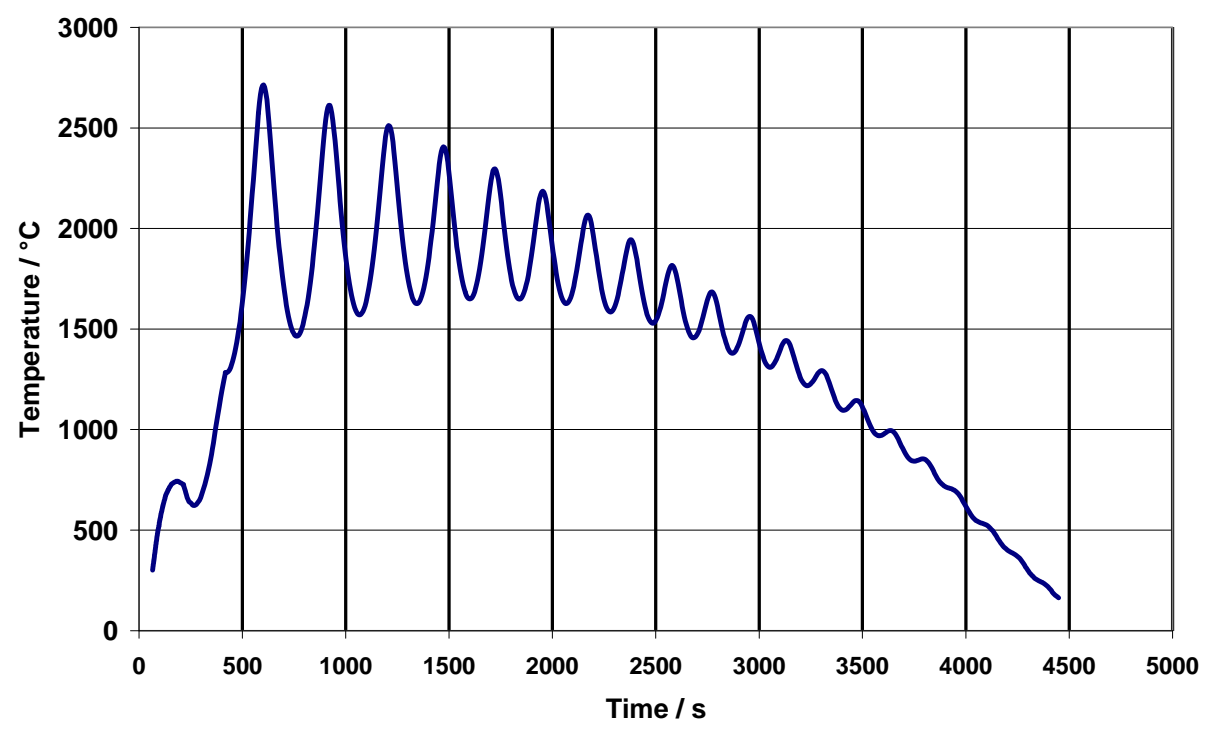

Figure 4. Heat flux history for the SpaceLiner nose with a nose radius of $1 \mathbf{~ m}$.

As shown above, the heat flux due to aerothermodynamic heating is strongly depending on the radius of the nose or the leading edge. If the radius is decreased for aerodynamic performance reasons the heat flux rises considerably to values that can only be handled with ablation or active cooling. If a radius of $0.01 \mathrm{~m}(10 \mathrm{~mm})$ is assumed for the leading edge of a large hypersonic vehicle, the maximum temperature of such an uncooled structure during the SpaceLiner flight goes up to over $5000^{\circ} \mathrm{C}$ as predicted by the DKR method and shown in Fig.5. This may not be fully correct, since the prediction for such small radii is uncertain, but it clearly shows the need to implement an actively cooled design if ablation is no option. This is even more underlined by the fact that a leading edge radius of $10 \mathrm{~mm}$ is still relatively large when compared e.g. to that of the X-43 leading edge radius which was 0.03 in which is $0.762 \mathrm{~mm}$, more than ten times smaller! 


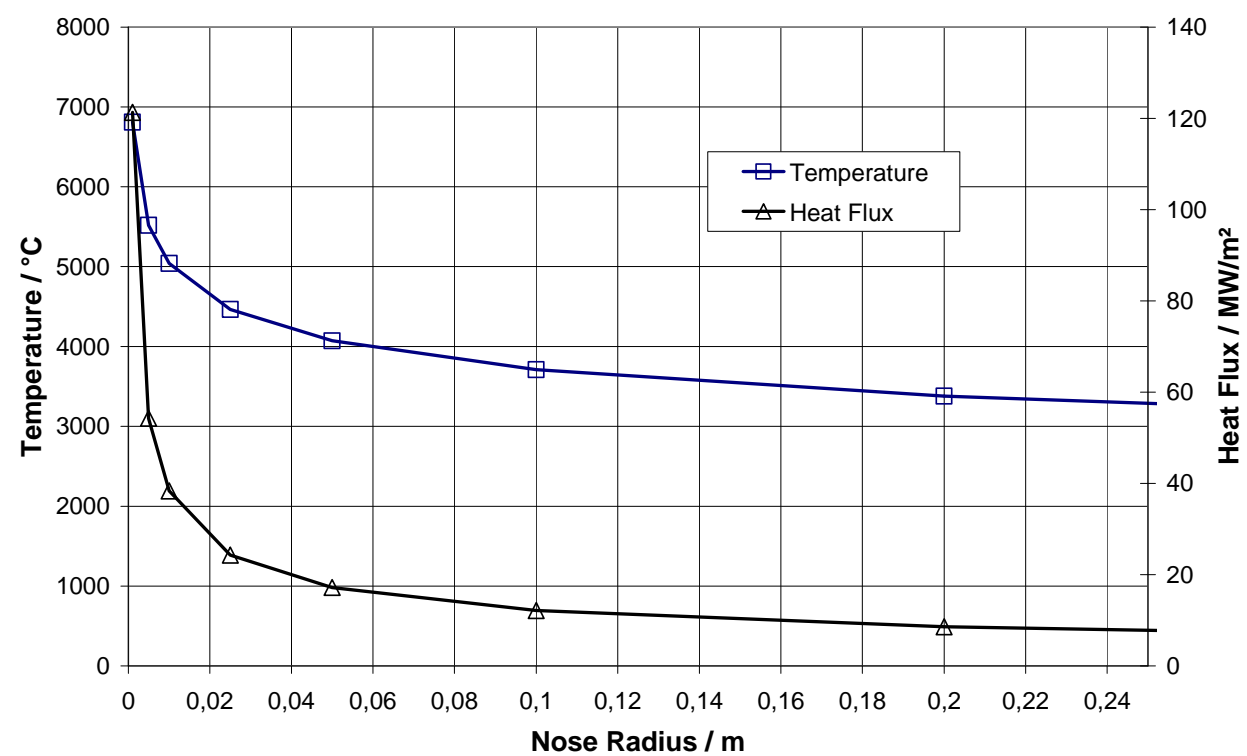

Figure 5. Maximum heat flux and temperature for the SpaceLiner depending on the nose radius III. Transpiration Cooling Test Design

In view of these demanding conditions a test program shall be carried out that investigates the technological basics required for active cooling of critical elements of hypersonic vehicles. The activities shall be carried out in the framework of the FAST20XX project funded by the European Union. The project acronym is derived from the full title "Future high-Altitude high-Speed Transport 20XX". The project aims at providing a sound technological foundation for the industrial introduction of advanced high-altitude high-speed transportation in the medium term (5-10 years) and in the longer run in the second half of this century by defining the most critical research, technology and development building blocks to achieve this goal. It is the objective of the project to evaluate two novel concepts for high-altitude high-speed transportation. The first is a low-energy concept that performs a suborbital flight after an air-launch or after an augmented horizontal ground launch. The second concept is the already discussed SpaceLiner, a high-energy concept that performs a long range flight at extremely high speeds without going fully into orbit.

Based on the experience with transpiration cooling already made in other projects a test program was defined. Tests were already carried out in different projects with different test articles in different environments. As mentioned, a thrust chamber was developed and tested in a liquid oxygen and hydrogen environment. In another project arc jet tests were conducted with flat CMC plates in which inserts were placed that were cooled by gaseous nitrogen and other gases ${ }^{10,11}$.

The major difference of the envisioned application on a hypersonic vehicle to the tests already done with transpiration cooling elements is the configuration of the critical elements on the hypersonic vehicle in a stagnation flow with corresponding high heat loads and also relatively high dynamic pressure. Therefore the test program was designed to reflect these issues.

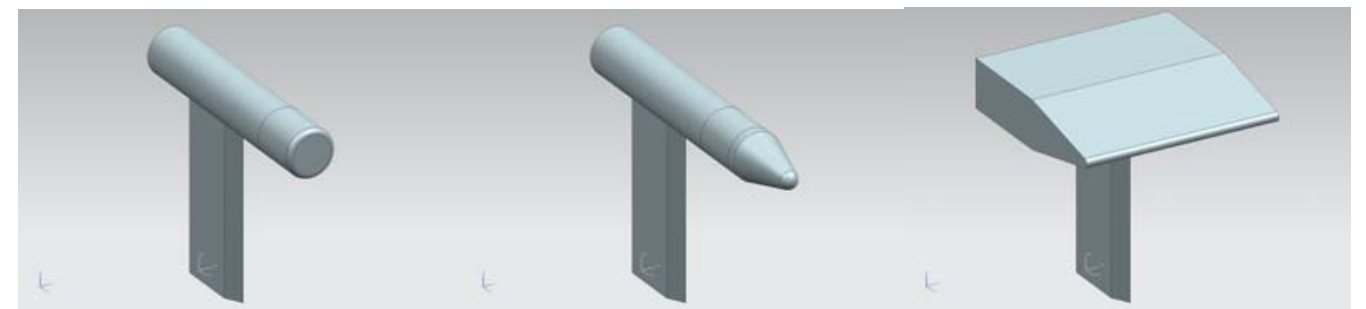

Figure 6. Configurations for the FAST20XX CMC transpiration cooling investigations 
The test program will consist of three campaigns with different configurations shown in Fig.6. The second and third configurations will be increasingly complex and at the same time the list of materials to be tested will be reduced going from the first to the second and third campaign.

In the first part of the test program a screening of different materials shall be carried out in a stagnation configuration with flat samples oriented normal to the flow direction. The tests shall be done in different flow conditions which shall be fixed in one test. The focus is on medium to high heat flux values with also relatively high stagnation total pressure. The cooling effectiveness will be tested by varying the coolant mass flow. Table 1 lists the materials selected for the first test campaign as well as the basic flow parameters.

In the second part of the test program which follows, the configuration will be changed into a cone with spherical tip. This adds to the problem the pressure distribution from stagnation along the sphere and over the cone but it is still an axially symmetric sample and there are good opportunities to compare against literature. The range of materials to be tested in that campaign shall be reduced from the first campaign.

Table 1. Description of first test campaign materials and test conditions.

\begin{tabular}{|l|l|}
\hline & \multicolumn{1}{c|}{$\begin{array}{c}\text { Test campaign 1 } \\
\text { Flat sample }\end{array}$} \\
\hline Materials & $\begin{array}{l}\mathrm{C} / \mathrm{C} \\
\mathrm{C} / \mathrm{C}-\mathrm{SiC} \\
\text { Ox-fibre CMC \#1 }\end{array}$ \\
\hline Coolant & $\begin{array}{l}\text { Water } \\
\text { Nitrogen gas } \\
\text { Argon gas }\end{array}$ \\
\hline Heat Load & $\begin{array}{l}\text { Reference test uncooled } @ \sim 1 \mathrm{MW} / \mathrm{m}^{2} \text { cold wall HF } \\
\text { Reference test cooled } \\
\text { High load case with cooling } @ \sim 4 \mathrm{MW} / \mathrm{m}^{2} \text { cold wall HF }\end{array}$ \\
\hline Pressure & Ref. test stagnation total pressure $\sim 70 \mathrm{kPa}$ \\
\hline
\end{tabular}

In the last part of the program the tests shall be carried out on a leading edge sample. The sample shall reflect critical technological issues to be encountered in the design of a wing leading edge. The sample will be manufactured from one material that came out as the best performing candidate from the first two campaigns. The focus will be on determining the cooling characteristics with regard to coolant mass flow, pressure, angle of attack and sweep angle variations.

\section{A. Materials and Samples}

The tests will be carried out with three types of materials. Samples will be produced from each material with varying fiber orientations. That is due to the fact that the properties of the materials are anisotropic also with regard to the permeability which is the key issue for the transpiration cooling. The materials are produced in the form of plates via the layup and subsequent processing of fiber textiles with a $0^{\circ} / 90^{\circ}$ weave.

In the case of the $\mathrm{C} / \mathrm{C}$ and the $\mathrm{C} / \mathrm{C}-\mathrm{SiC}$ material the processing starts out with the same CFRP production. Carbon fiber textiles are impregnated with a phenolic resin in an autoclave process. After the curing the plates are given into a carbonization or pyrolysis process. At temperatures up to $1600^{\circ} \mathrm{C}$ the phenolic matrix is converted into amorphous carbon. In the case of $\mathrm{C} / \mathrm{C}$, the process stops and samples are manufactured. To arrive at the $\mathrm{C} / \mathrm{C}-\mathrm{SiC}$ material, the $\mathrm{C} / \mathrm{C}$ plates are infiltrated with silicon via a melt infiltration process during which the amorphous carbon as the remainder of the matrix and to some extent the fibers react with the liquid silicon to form $\mathrm{SiC}$ as the new matrix. Since the porosity of the resulting material is very low, advantage is taken from the effect that a certain percentage of the matrix volume is occupied by free silicon that did not convert. When the $\mathrm{C} / \mathrm{C}-\mathrm{SiC}$ is heated up in another processing step without offering additional silicon, the free silicon can be liquefied again and drawn out of the material, thus raising the porosity a little bit which enhances the permeability and should be beneficial for the cooling effect. 
Table 2. Sample types and fiber orientation

\begin{tabular}{lc}
\hline \hline \multicolumn{1}{c}{ Material Type } & $\begin{array}{c}\text { Fibre orientation } \\
\text { relative to flow direction }\end{array}$ \\
\hline Carbon / Carbon (C/C) & Perpendicular \\
& $+/-45^{\circ}$ \\
& Parallel \\
\hline Carbon / Carbon - Silicon Carbide (C/C-SiC) & Perpendicular \\
& $+/-45^{\circ}$ \\
\hline Oxide fiber CMC & Parallel \\
\hline \hline
\end{tabular}

In Fig. 7 a sample is shown along with one of the CMC tubes ready to be assembled. Fig. 8 depicts the test assembly before the test.

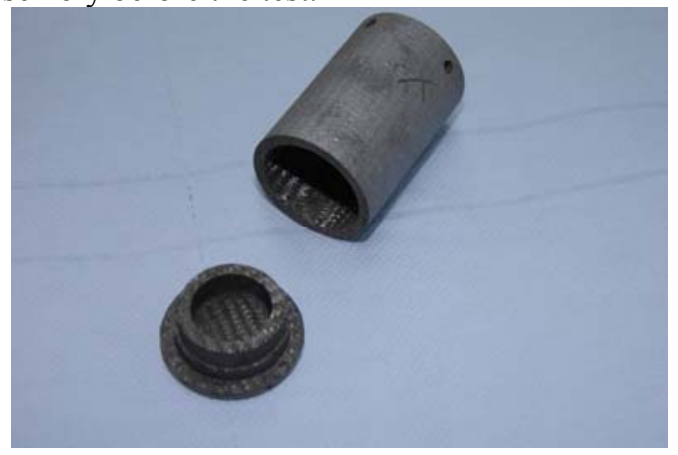

Figure 7. Sample and tube

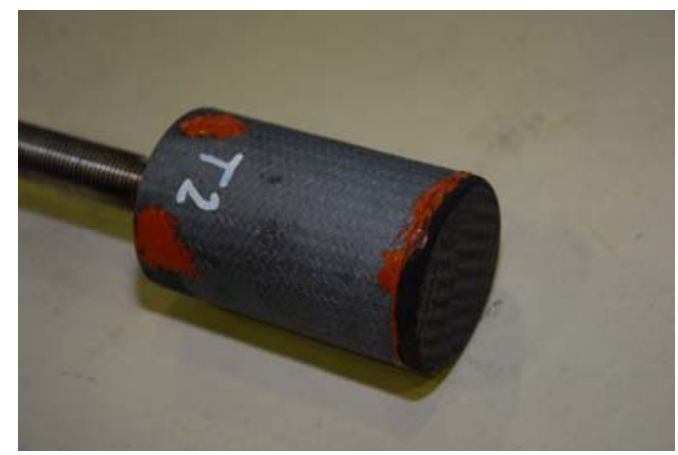

Figure 8. Test assembly

\section{B. Test Design}

A setup for the tests was designed that should be simple, low cost and use existing experience. In Fig. 9 a cross section of the test assembly is presented.

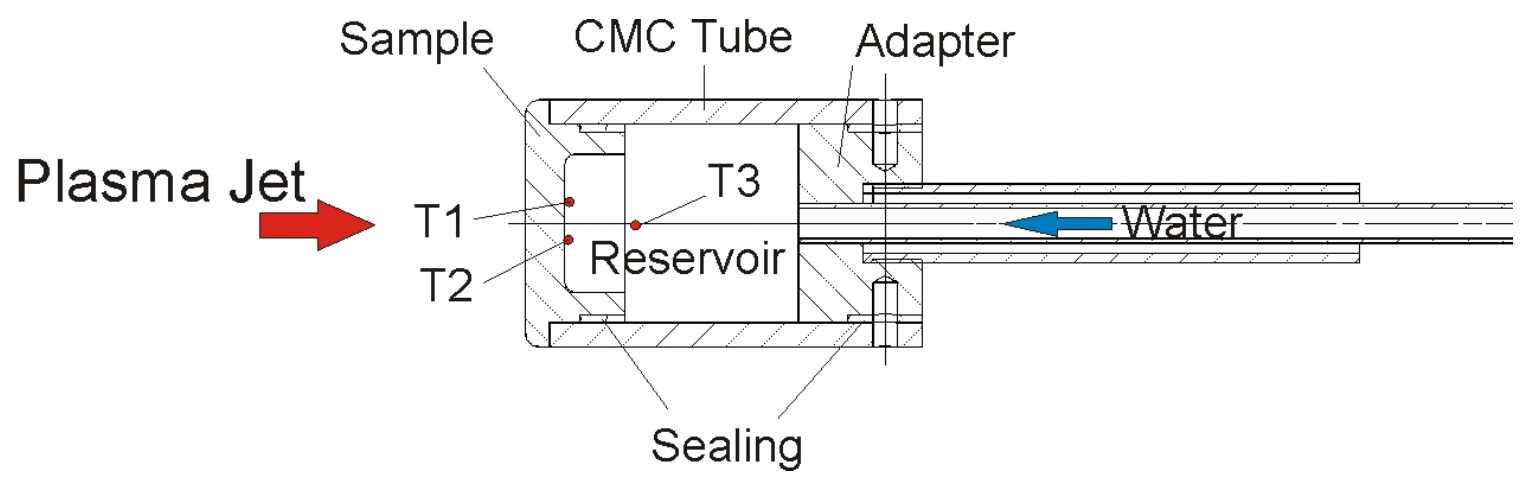

Figure 9. Schematic of the test set-up

One of the standard test setups for the LBK facility in Cologne uses samples of 50mm diameter. It was decided to select that size for the screening tests. The sample geometry is a flat disk with its surface normal oriented along 
the nozzle axis/flow direction of the arc jet facility. The main components of the set-up are the sample, a ceramic tube and a metallic adapter to which the tube is connected. Inside of the assembly of sample, tube and adapter, a reservoir is created that should be filled with water during the test.

\section{Tests}

\section{A. Pre-Tests}

Before going into the arc-jet, the set-up was tested for leakage and for determining the ultimate strength of the foreseen adhesive joint between tube and sample.

A C/C sample was glued into an aluminum cylinder into which a hole had been drilled on one end to take up the sample. A smaller hole extended through the cylinder until at the far end a fitting was connected to a pressure supply. The internal volume was stepwise put under air pressure. At each step the corresponding mass flow was measured. At a pressure of roughly seven atm the assembly failed. The sample fractured due to interlaminar failure and the top of the sample was blown away. The adhesive joint of the sample collar in the tube did not fail.

In order to determine the sealing between reservoir tube and sample resp. between reservoir tube and steel adapter a $\mathrm{C} / \mathrm{C}$ sample was glued into a $\mathrm{C} / \mathrm{C}-\mathrm{SiC}$ tube with the foreseen graphite adhesive. Sample and tube were then joined to the steel adapter again using the graphite adhesive. A $\mathrm{C} / \mathrm{C}$ sample was selected because it has the largest permeability values and was foreseen for the first tests since there is considerable experience from $\mathrm{C} / \mathrm{C}$ transpiration cooling tests with gas as the coolant.

All valves of the water supply were closed initially. Then the main valve of the water supply was fully opened and the needle valve was subsequently carefully opened until water was observed on the front face of the sample. Between needle valve and sample the mass flow meter is located. Between mass flow meter and the sample the pressure gauge is located.

When the first signs of water on the sample front were observed, the needle valve was left in that position until a steady state condition was achieved. After reaching steady-state, the valve was opened further to record data about the mass flow rate at specific pressure values.

When a certain pressure was reached and the valve was opened further again, the pressure suddenly dropped to a low level indicating that a leak had opened. Water was leaking out of the joint between the sample and the ceramic tube. No water could be observed coming out of the sample front any more but everything was leaking out at the joint. Another leak developed at the rear of the assembly at the joint between the tube and the steel adapter.

It was decided to seal the leaks via a makeshift repair with epoxy resin without taking the assembly apart. After re-sealing the pre-test could be carried out up to a pressure difference of about 1 atm without problems. The recorded mass flow values were in the range of $0-0.5 \mathrm{~g} / \mathrm{sec}$ of water.

The same test with the same assembly was repeated in the lab in Stuttgart to acquire more detailed data in the low pressure / low mass flow regime. Pressure levels were set and the corresponding mass flow was measured.

\section{B. Sealant replacement}

After the unfavourable experience with the originally foreseen graphite adhesive the sealant was replaced by a room temperature vulcanizing high-temperature silicone to enhance the sealing performance.

\section{Arc Jet Testing}

\section{First test}

Five test assemblies were prepared from $\mathrm{C} / \mathrm{C}$ samples and the ceramic tubes. The sealant was RTV silicone. The first sample was mounted into the tunnel on the holder. The water supply line and the thermocouples were connected. The main valve of the water cooling supply, the needle valve for the fine tuning and the magnet valve in the tunnel were closed. In order to feed water into the test assembly, first the main valve was opened, then the magnet valve was opened and finally the needle valve was opened until a reading on the mass flow meter could be observed. Different levels of water cooling mass flow were set with the needle valve. During the procedure, the test 
assembly was checked for leakage. No leakage was detected. After that the magnet valve was closed again, main valve was left open and the needle valve was set to the desired position. In that configuration the tunnel was evacuated until ignition could be carried out.

In Fig. 10 the test assembly can be seen with water drops forming on the surface of the sample. There is a good and fine distribution of the water droplets that eventually grow together into bigger drops which then run down the sample to fall of.

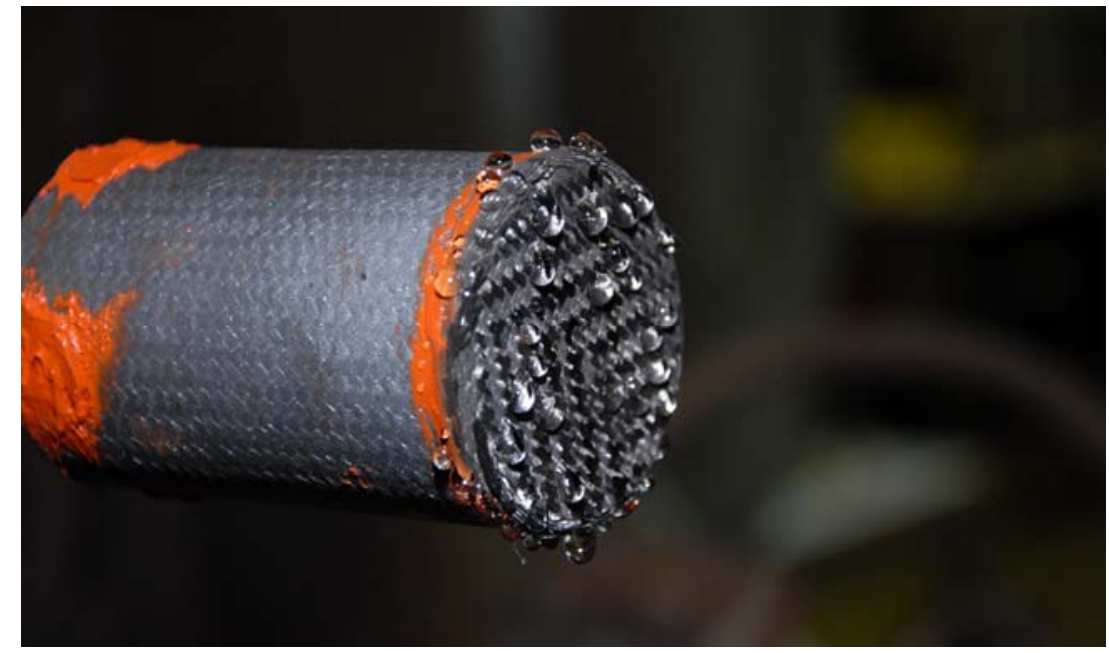

Figure 10. Second test assembly during water cooling supply check.

After the jet had stabilized the model was inserted into the plasma jet. The surface temperature quickly rose to rather high values. An image taken during the test reveals that ice had formed on the sample. It is visible around the circumference of the sample. Shortly after the image was taken the test was aborted and the sample rotated out of the plasma jet.

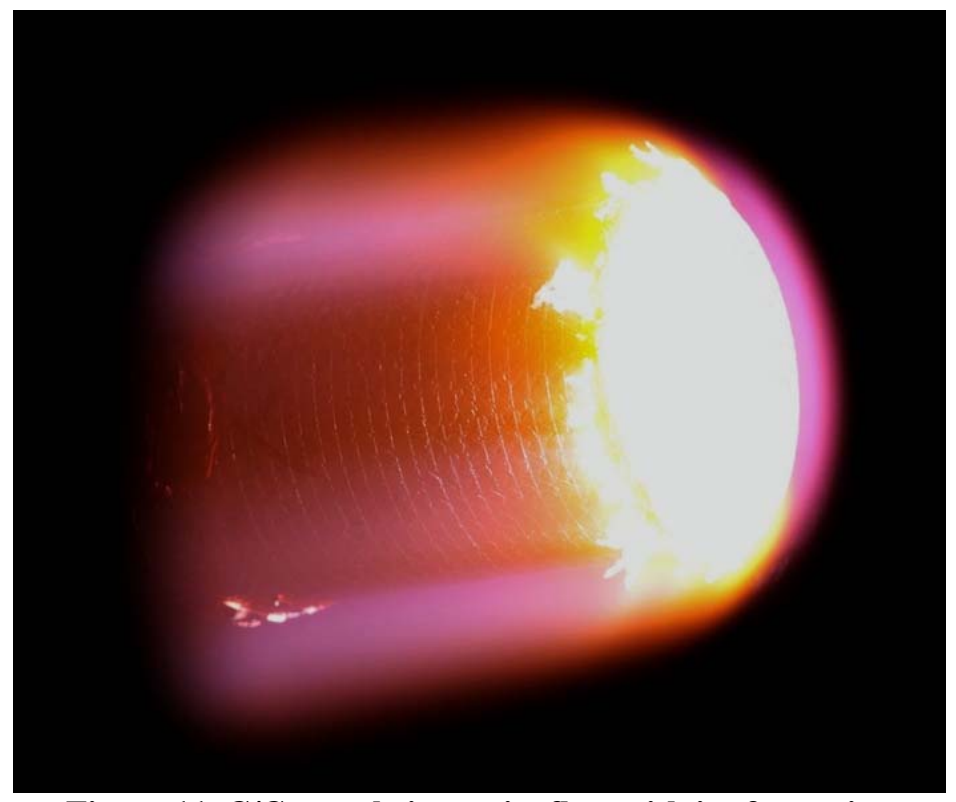

Figure 11. C/C sample in arc jet flow with ice formation 


\section{Ice Formation}

The question if ice is forming on the sample was discussed before the tests. It was observed during the tests of van Foreest that large amounts of ice can form on the surface of the test article. Even when the sample is injected into the plasma jet, the ice is not removed immediately but stays. That can be a problem for the intended transpiration cooling effect because the ice can block the transport of the water.

During the first test when the tunnel was evacuated, it could indeed be observed that the temperatures inside the test assembly were constantly falling. Also the observation via an infrared camera indicated that temperatures on the sample surface had gone below zero degrees Celsius at roughly 6 mbar tunnel pressure. In the end, just before insertion of the model in the jet, the temperatures on the sample inside were around $-2^{\circ} \mathrm{C}$.

An inspection of the sample after the test showed no indications of damage to the sample. It was planned to carry out another test with the same sample, however, during changing the magnet valve a pressure pulse in the test assembly pushed out the sample from the $\mathrm{C} / \mathrm{C}-\mathrm{SiC}$ tube, thereby destroying it. The main water supply has a pressure of 7 bar. That value had built up in front of the magnet valve. When the valve was opened for functional checking with the needle valve also open, the high pressure acted on the sample.

\section{Second test}

A second test was carried out with another sample. In principle the set-up and the planned procedure were identical. Only the cooling water supply was changed in order to avoid the high pressure levels from the main supply line. Instead a reservoir was installed on an upper level of the facility building with a water line running down to the wind tunnel with the test assembly. With this kind of water supply the pressure is limited to the hydrostatic pressure as a result of the reservoir height over the sample. The height was roughly 5 meters. As for the first test, the mass flow levels were checked prior to the actual test to verify the set up. The result was satisfying and it was decided to carry out the test in the same way with a wet water supply in the test assembly.

During the second test a photograph was made immediately afer the model had reached the position on the axis of the jet centerline which is shown in Fig.12. Ice streaks are visible around the circumference of the sample. On the lower edge of the sample ( $7 \mathrm{o}^{\prime}$ clock position) the temperature is already going up and the sample starts to glow.

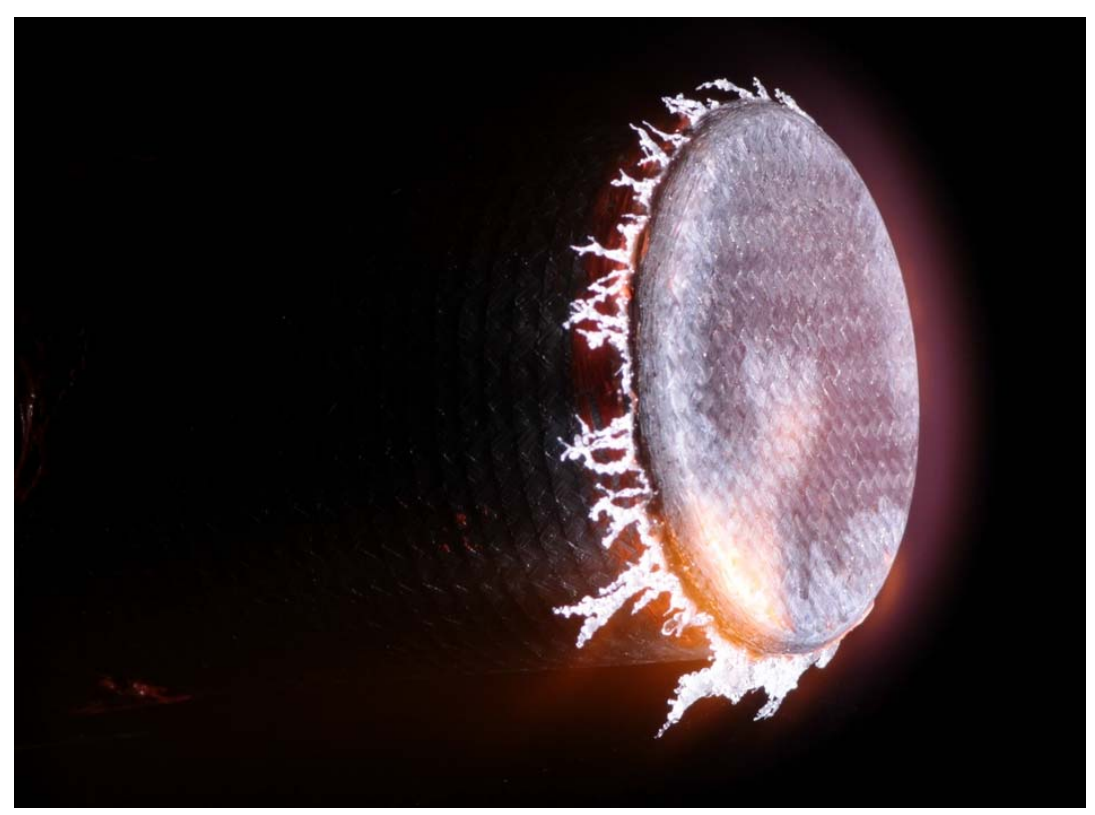

Figure 12. View of second test sample immediately after insertion into jet with ice streaks surrounding the sample 


\section{Measured Surface Temperatures}

In Fig. 13 the measured surface temperatures of both tests are shown. The first test lasted for about 10 s, the second for $16 \mathrm{~s}$. The sample surface temperature climbs to $1100^{\circ} \mathrm{C}$ for the first test and $1400^{\circ} \mathrm{C}$ for the second test. Although the arc jet conditions were identical, there is a notional difference in the surface temperature of the two tests. It is not yet clear where the difference comes from. For both tests there seems to be little if any cooling effect.

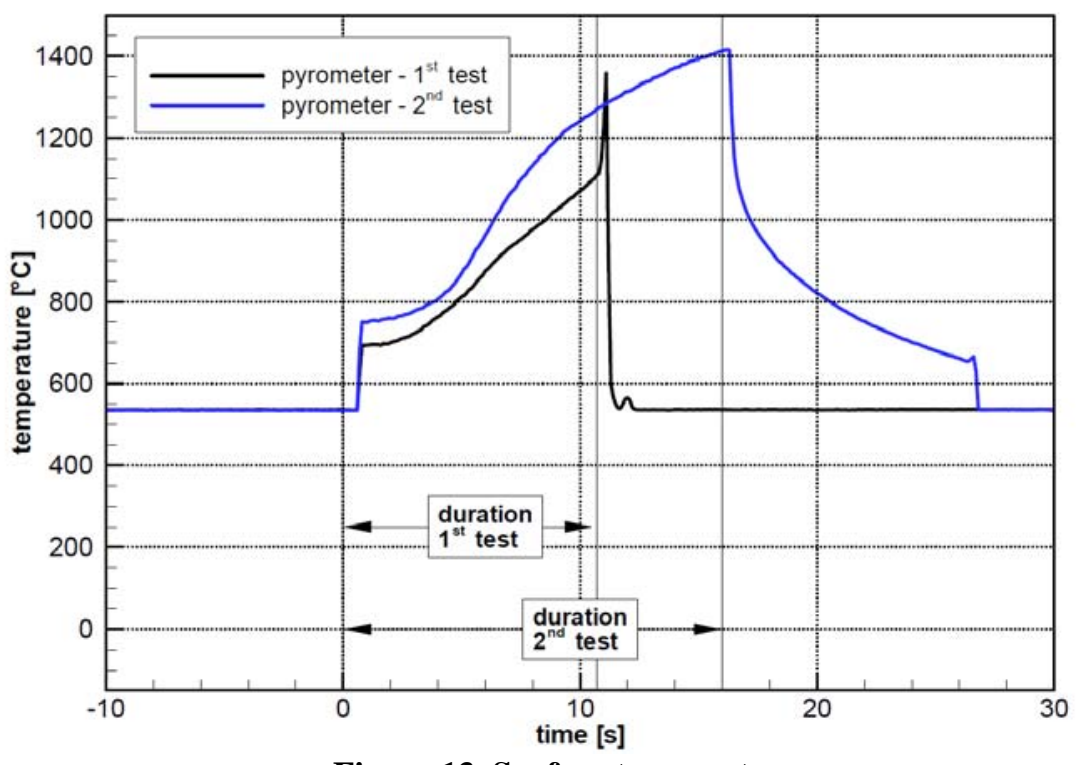

\section{Reservoir Temperatures}

Figure 13. Surface temperatures

The measured reservoir temperatures are presented in Fig. 14. For the first test it climbs up to $58^{\circ} \mathrm{C}$, for the second test $100^{\circ} \mathrm{C}$ is reached. The reservoir temperature data shows even more that there was a considerable difference between the two tests. The temperature of the water supply is roughly at $20^{\circ} \mathrm{C}$. The reservoir temperature has dropped considerably due to the evacuation of the tunnel test chamber and is close to zero degrees for both tests.

Towards the end of the second test, the reservoir temperature reached $100^{\circ} \mathrm{C}$. When the model was rotated out of the jet, the test assembly was still in good condition. However, when the tunnel chamber was opened, the sample had vanished from the tube! That was obviously a result of developing steam along with rising pressure that eventually pushed the sample out of the tube. The sample could be found in the tunnel test chamber.

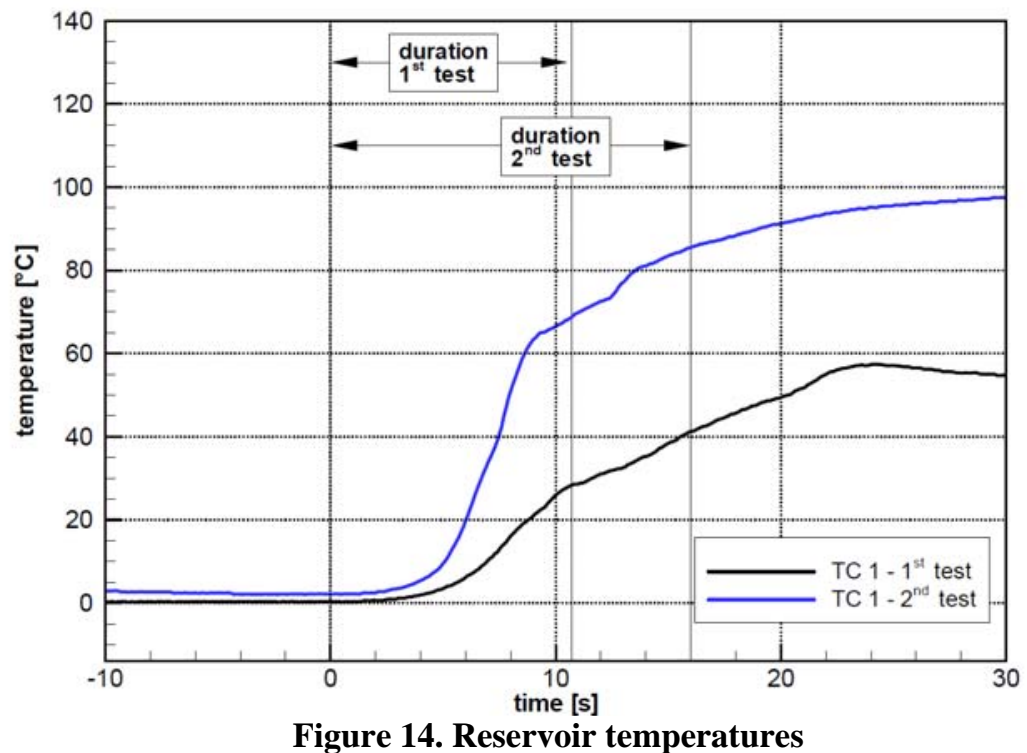




\section{Coolant Mass Flow}

The coolant mass flow was measured with a coriolis-type mass-flow meter. It was found to be difficult to interprete with unexplainable fluctuations. The values had a lot of scatter.

When the measurement set-up and the coolant supply was revised after the first two tests, it was found that the mass flow readings for these initial tests were unreliable due to an unfavourable position of the mass flow meter after the needle valve on the low-pressure side. After a change in the set-up the readings for a third next test were more consistent in a range of $0.1 \mathrm{~g} / \mathrm{s}$. It was concluded from the observations of the pre-tests checks with the water dripping out of the sample that the mass flow for the first tests were in the range below $0.1 \mathrm{~g} / \mathrm{s}$ which also explains that almost no cooling effect could be observed.

\section{Conclusion}

Two initial tests of a wide screening campaign have been carried out on the topic of transpiration cooling for highly loaded structural elements of hypersonic flight vehicles. The campaign had to be postponed due to the usual reasons with sample manufacturing and preparations, so that only very preliminary results can be presented that highlight the troubles that are always coming up when new testing ground is entered.

The tests were carried out with $\mathrm{C} / \mathrm{C}$ samples mounted on a $\mathrm{C} / \mathrm{C}-\mathrm{SiC}$ tube. The $\mathrm{C} / \mathrm{C}$ material was selected for the initial tests because there is a good experimental basis with it in terms of using gas as the coolant for the transpiration cooling. The selected set-up was chosen because there is also a good experience with it in terms of material testing under high heat load conditions that lead to oxidation and erosion.

Among the issues that need to be resolved was that the coolant supply did not work as aniticipated. That was probably due to the ice formation issue which was expected in some way. The measurement of the coolant mass flow rates was also not reliable but could be improved already. Temperatures of the samples were in the range of $1100^{\circ} \mathrm{C}-1400^{\circ} \mathrm{C}$ which is much more than was expected. If the ice issue can not be resolved by a suitable procedure (like pre-heating the sample or the coolant) is to add alcohol to the coolant to lower its freezing point.

\section{Acknowledgments}

Thomas Reimer wants to thank the DLR folks in Cologne operating the arc jet tunnel as usual in their professional way and providing last-minute inputs to the paper.

\section{References}

${ }^{1}$ J. J. Bertin, "Hypersonic Aerothermodynamics", AIAA 1993, ISBN 978-1563470363

${ }^{2}$ H. Weihs, H. Hald, T. Reimer, I. Fischer, "Development of a CMC Nose Cap for X-38”, IAF-01-I.3.01, 52International Astronautical Congress, Toulouse, 1.-5. October 2001

${ }^{3}$ H. Hald, P. Winkelmann, "Post Mission Analysis of the Heat Shield Experiment CETEX for the

EXPRESS Capsule", 48th IAF Congress, October 6-10, 1997, Turin, IAF-97-I.4.01

${ }^{4}$ T. Reimer, K. Stubicar, G. Koppenwallner, R. M. Müller-Eigner, S. Lein, A. Steinbeck, "Overview about the Instrumented Nose Assembly Development for the EXPERT Capsule", 16th AIAA DLR DGLR International Space Planes and Hypersonic Systems and Technologies Conference, Oct. 19-22, 2009, Bremen, Germany

${ }^{5}$ J. M. Longo, J. Turner H. Weihs, "SHEFEX II - Aerodynamic Re-Entry Controlled Sharp Edge Flight Experiment", 6th European Symposium on Aerothermodynamics for Space Vehicles , Nov. 03-06, 2008, Versailles, France

${ }^{6}$ J. Marschall, D. A. Pejakovic, W. G. Fahrenholtz, G. E. Hilmas, S. Zhu, J. Ridge, D. G. Fletcher, C. O. Asma, J. Thömel, "Oxidation of $\mathrm{ZrB}_{2}-\mathrm{SiC}$ Ultrahigh-Temperature Ceramic Composites in Dissociated Air", Journal of Thermophysics and Heat Transfer, Vol. 23, No. 2, April-June 2009

${ }^{7}$ H. Hald, A. Herbertz, M. Kuh, M. Ortelt, "Technological Aspects of Transpiration Cooled Composite Structures for Thrust Chamber Applications", 16th AIAA DLR DGLR International Space Planes and Hypersonic Systems and Technologies Conference, Oct. 19-22, 2009, Bremen, Germany 
${ }^{8}$ A. van Foreest, M. Sippel, A. Gülhan, B. Esser, B. A. C. Ambrosius, K. Sudmeijer, "Transpiration Cooling Using Liquid Water", Journal of Thermophysics and Heat Transfer, Vol. 23, No. 4, October-December 2009

${ }^{9}$ M. Sippel, A. van Foreest, "Latest Progress in Research on the SpaceLiner High-Speed Passenger Transportation Concept", International Astronautical Congress, 2007, IAC-07-D2.7.07

${ }^{10}$ A. Gülhan (Editor), "RESPACE - Key Technologies for Reusable Space Systems", Springer, 2008, Berlin Heidelberg

${ }^{11}$ B. Esser, A. Gülhan, M. Kuhn, "Thermal Qualification of Transpiration Cooling for Atmospheric Entry", CEAS, Berlin, p. 3205-3210 